\title{
Alteração das concentrações de nitrogênio e fósforo na bacia do rio Apodi- Mossoró em função dos efeitos da estiagem e espacialidade
}

\author{
Adriene Kelly Gois Oliveira ${ }^{1}$; (Graduando em Química na Universidade do Estado do Rio \\ Grande do Norte - UERN)
}

Luiz Di Souza²; (Prof. Adjunto do DQ e do PPGCN na Universidade do Estado do Rio Grande do Norte - UERN)

Email: adriene_ibn@hotmail.com

\section{RESUMO}

O rio Apodi-Mossoró, segundo maior rio potiguar, tem sofrido grandes prejuízos devido sua alta poluição, decorrente da ação antrópica em torno dele e das condições que o envolve. Dentre os diversos poluentes que afetam o rio, o presente trabalho propõe relacionar o teor de compostos de nitrogênio e fósforo com a diminuição do volume de água que a bacia hidrográfica do rio Apodi-Mossoró tem sofrido nos últimos cinco anos. Para a elaboração do mesmo foram feitas análises colorimétricas de $\mathrm{PO}_{4 \text { total, }} \mathrm{N}$ total e nitrogênio amoniacal em dezoito pontos de coleta em açudes, barragens e propriedades banhadas pelo rio, os resultados foram correlacionados ao fator climático da região semiárida. Os resultados mostraram que a temperatura do semiárido favorece a evaporação de seus reservatórios e o período longo de estiagem faz com que os reservatórios apresentem baixo volume de água, devido a estes fatos o teor de fósforo tem diminuído na zona rural, pois não houve carreamento de resíduos agrícolas (fertilizantes) que é a principal fonte desse nutriente na área, já na zona urbana onde a principal fonte são os esgotos domésticos, houve variação mínima ou aumento. O mesmo pode ser dito com relação ao teor de nitrogênio na água das áreas examinadas, pois o nitrogênio e fósforo apresentam fontes de contaminação similares. Por outro lado, a amônia por ser um indicador de fonte de poluição próxima, apresenta elevação em seus níveis nos pontos analisados, pois há acumulação da mesma devido à escassez hídrica.

Palavras chave: Água superficial; Indicadores de qualidade; Corpo hídrico

\section{NTRODUÇÃO}

A água é essencial para a manutenção da vida no planeta, porém, em qualidade desfavorável, ou seja, contaminada e com substâncias tóxicas, a mesma se torna um risco para o homem e organismos aquáticos. Dentre os diversos contaminantes presentes hoje nos corpos d'água, o nitrogênio e o fósforo destacam-se por serem os principais nutrientes causadores da eutrofização, um fenômeno poluidor de características bastante complexas.

O nitrogênio pode ser encontrado na água na forma reduzida: nitrogênio orgânico e amoniacal e, também, na forma oxidada: nitrito e nitrato, já o fósforo aparece nas águas na forma de fosfatos orgânicos, ortofosfatos e polifosfatos. A principal fonte de nitrogênio e fósforo nas águas naturais são os esgotos sanitários, além de efluentes da agricultura e industriais (PIVELI, 2005).

O consumo de nitrato através das águas de abastecimento está associado a dois efeitos adversos à saúde: a indução à metemoglobinemia, especialmente em crianças, e a formação potencial de nitrosaminas e nitrosamidas carcinogênicas. O nitrito, quando presente na água de consumo humano, tem um efeito mais rápido e pronunciado do que o nitrato. Se o nitrito for ingerido, diretamente, pode ocasionar metemoglobinemia independente da faixa etária do consumidor (ALABURDA, 1998).

No que se refere à saúde, o enriquecimento da água com o fósforo não traz maiores problemas, já que se trata de um elemento requerido em elevadas quantidades pelos animais. 
Entretanto, esse enriquecimento traz sérios problemas em termos de desequilíbrio dos ecossistemas aquáticos, devido ao processo de eutrofização (RESENDE, 2002).

A resolução CONAMA n ${ }^{\circ}$ 357, DE 17 DE MARÇO DE 2005 classifica os corpos d'água e as diretrizes ambientais para o seu enquadramento, assim como estabelece as condições e padrões de lançamentos de efluentes, e dá outras providências, porém o nitrogênio total não é padrão de referência da mesma.

O Brasil possui uma das mais extensas e diversificadas redes fluviais do mundo, dividida em 12 regiões hidrográficas. A Bacia hidrográfica do Atlântico Nordeste Oriental não tem grandes rios e, por isso, apresenta baixa disponibilidade de água em relação à demanda local, principalmente, em períodos de estiagem. Os $287.348 \mathrm{~km}^{2}$ dessa bacia atingem cinco Estados do Nordeste e suas capitais (Ceará, Rio Grande do Norte, Paraíba, Pernambuco e Alagoas), dezenas de núcleos urbanos e um grande parque industrial. Além disso, a região reúne diversas bacias costeiras de pouca extensão. As reservas hídricas dessa região diminuíram drasticamente nos últimos anos como ilustra a Figura 1.

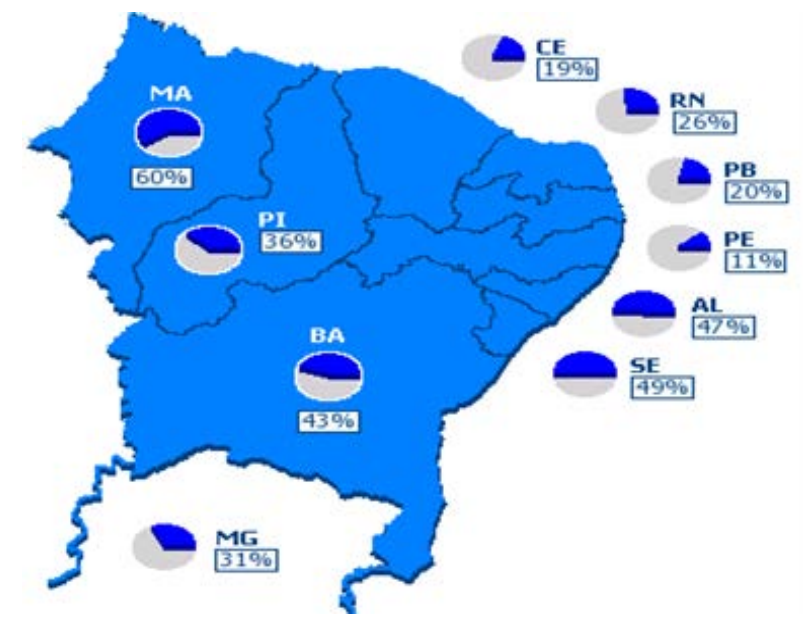

Figura 1. Resumos dos recursos hidricos disponiveis no nordeste em setembro de 2011. Fonte: Site DNOCS.http://www.dnocs.gov.br/php/canais/recursos_hidricos/

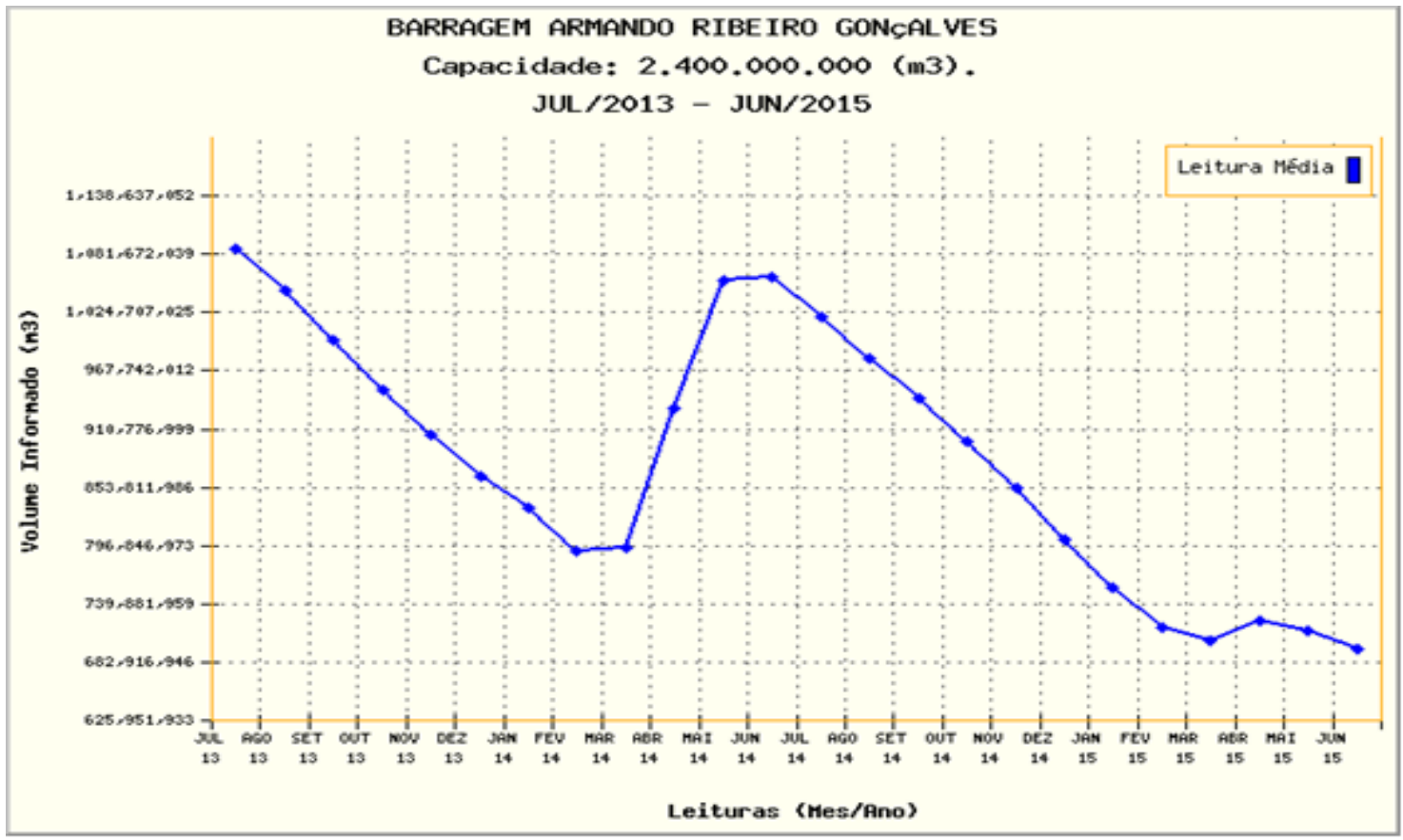

Gráfico 1. Volume $\left(\mathrm{m}^{3}\right)$ da barragem Armando Ribeiro Gonçalves nos anos de 2013 - 2015.

Fonte: Site DNOC

Shttp://www.dnocs.gov.br/dnocs/php/comunicacao/monitoramento_de_reservatorios.php 
Com a seca dos últimos anos os reservatórios (açudes e barragens) não tem recuperado o seu nivel de acumulação como ilustra o Gráfico 1. para o reservatório armando Ribeiro gonçalves que é o maior da região. O mesmo mostra que em meados de junho/julho de 2013 os reservatórios apresentavam o maior volume em $\mathrm{m}^{3}$ de água, devido as precipitações pluviométricas deste período, voltando a diminuir no período de estiagem em meados de fevereiro/março, porém, a falta de precipitações pluviométricas que tem assolado a região faz com que o volume do reservatório se tornasse cada vez mais baixo que nos anos anteriores, desde o ano de 2011, quando se iniciou a estiagem.

O presente trabalho teve por objetivo coletar amostras e avaliar a presença de compostos de nitrogênio e fósforo em dezoito pontos de coleta de águas superficiais da bacia hidrográfica do rio Apodi-Mossoró no Rio Grande do Norte e correlacioná-los aos valores obtidos no intervalo de cinco anos (2011 a 2015), visando determinar quais efeitos estes cinco anos de seca severa influenciaram a região e quais suas consequências nos recursos hídricos.

\section{MATERIAIS E MÉTODOS}

A bacia hidrográfica do rio Apodi/Mossoró, segunda maior do RN, nasce no município de Luiz Gomes, que faz divisa com o Estado da Paraíba, e deságua no mar entre as cidades de Grossos e Areia Branca. No geral os rios desta região apresentam um regime hidrológico do tipo temporário. A mesma é considerada como fator de desenvolvimento para região, pelas diversas atividades econômicas desenvolvidas no seu entorno. Apesar de sua importância, este recurso vem sofrendo sérios desequilíbrios em seu ecossistema, decorrentes dos constantes despejos de efluentes e resíduos domésticos e industriais (OLIVEIRA, 2009).

A vazão do rio Apodi-Mossoró é de aproximadamente 360 milhões de $\mathrm{m}^{3} / \mathrm{ano}$, com o escoamento iniciando no mês de fevereiro e, diminuindo, drasticamente a partir do mês de junho, tornando-se praticamente nulo nos meses de novembro e dezembro. Isto se deve ao clima semiárido da região, que favorece os altos índices de evaporação e à escassez de água, conforme dados pluviométricos de alguns municípios distribuídos ao longo da bacia (OLIVEIRA, 2011).

As amostras foram coletadas na bacia do rio Apodi/Mossoró por técnicos que trabalham no programa Água azul, entregues no laboratório de catalise, ambiente e materiais (LACAM), da Universidade do Estado do Rio Grande do Norte, em recipientes apropriados, devidamente resfriadas com gelo e conservadas, quimicamente, quando necessário.

No laboratório foram filtradas e analisadas pelo método colorimétrico segundo a metodologia padrão (APHA, 2005). Foram usadas vidrarias comuns de laboratório, autoclave para as análises de nitrogênio e fósforo total e o espectrofotômetro UV-vis da Shimadzu modelo UV mini 1240 nas condições adequadas. O método usado no UV-vis foi o quantitativo, com o valor das amostras, sendo comparado com os de uma curva padrão feita no aparelho e os resultados sendo fornecidos automaticamente em ppm. Todas as amostras foram analisadas em triplicata, sendo o resultado a média aritmética delas.

\section{RESULTADOS E DI SCUSSÃO}

Os resultados obtidos nas análises de $\mathrm{PO}_{4}$ total, $\mathrm{N}$ total e $\mathrm{NH}_{3}$ são apresentados na Tabela 1 , na qual podem ser vistos valores próximos em alguns dos pontos, porém, observa-se também valores distantes dos demais, apresentando aumento ou diminuição desproporcional aos valores obtidos na maioria dos pontos de coleta, como é o caso de malhada vermelha que apresentou diminuição com relação ao teor de fósforo, em A. S Antonhio houve diminuição no teor de fósforo e nitrogênio total, os resultados apresentaram também aumento no teor de nitrogênio amoniacal em diversos pontos, sendo poucos os pontos em que houve diminuição do mesmo. Estes resultados foram semelhantes aos obtidos por Castro et al. (2007, 2011, 2012 A e B e 2013) e por Silva e Souza (2013). 
Tabela 1: Teores de $\mathrm{PO}_{4}$ total, $\mathrm{N}$ e $\mathrm{NH}_{3}$ em pontos específicos da bacia hidrográfica do rio ApodiMossoró em julho de 2011 e julho de 2015

\begin{tabular}{ccccccc}
\hline Pontos/propriedades & $\begin{array}{c}\mathrm{PO}_{4 \text { total }} \\
\mathbf{2 0 1 1}\end{array}$ & $\begin{array}{c}\mathrm{PO}_{4 \text { total }} \\
\mathbf{2 0 1 5}\end{array}$ & $\begin{array}{c}\mathbf{N}_{\text {total }} \\
\mathbf{2 0 1 1}\end{array}$ & $\begin{array}{c}\mathrm{N}_{\text {total }} \\
\mathbf{2 0 1 5}\end{array}$ & $\begin{array}{c}\mathbf{N H}_{\mathbf{3}} \\
\mathbf{2 0 1 1}\end{array}$ & $\begin{array}{c}\mathbf{N H}_{\mathbf{3}} \\
\mathbf{2 0 1 5}\end{array}$ \\
\hline $\begin{array}{c}\mathrm{mg} / \mathrm{l} \\
\text { Padrão }\end{array}$ & $\mathrm{mg} / \mathrm{l}$ & $\mathrm{mg} / \mathrm{l}$ & $\mathrm{mg} / \mathrm{l}$ & $\mathrm{mg} / \mathrm{l}$ & $\mathrm{mg} / \mathrm{l}$ \\
\hline CONAMA 357/05 & 0,15 & 0,15 & - & - & - & - \\
\hline A. Branca-estuário & 0,5377 & 0,0098 & 1,7442 & 0,1272 & 0,0853 & 0,1212 \\
\hline P. de Pedras & 0,4071 & 0,0128 & 8,4478 & 0,453 & 0,1517 & 0,3803 \\
\hline Ponte BR 110 & 0,3663 & 0,0263 & 1,0199 & 1,0311 & 0,08 & 0,0174 \\
\hline M. Vermelha & 6,7422 & 0,0151 & 2,7453 & 0,2131 & 0,0044 & 0,1648 \\
\hline Gover. D. Rosado & 0,3808 & 0,0129 & 0,1651 & 0,3357 & 0,041 & 0,0135 \\
\hline A.S. Antonhio & 1,9051 & 0,0085 & 6,7364 & 0,5767 & 0,0536 & 0,3511 \\
\hline Bar. do Genésio & 0,3228 & 0,0109 & 0,091 & 0,2247 & 0,0424 & 0,0241 \\
\hline R.C. F Angicos & 0,1586 & 0,0111 & 1,0691 & 0,206 & 0,0452 & 0,015 \\
\hline Açude Lucrecia & 0,1681 & 0,373 & 0,0221 & 4,1368 & 1,0884 & 4,4515 \\
\hline Açude Morcego & 0,4205 & 0,332 & 4,4028 & 2,4527 & 0,0813 & 0,8616 \\
\hline Açude Passagem & 0,1608 & 0,2739 & 1,152 & 2,5498 & 0,0719 & 0,6298 \\
\hline Açude Rodeador & 0,4316 & 0,4587 & 0,4978 & 1,126 & 0,023 & 1,2091 \\
\hline Açude Tourão & 0,3752 & 0,4015 & 3,0263 & 3,3262 & 0,053 & 0,839 \\
\hline Açude Bonito II & 0,2736 & 0,3571 & 0,9166 & 1,8434 & 0,0504 & 1,59 \\
\hline Açude Encanto & 0,2463 & 0,3698 & 1,2059 & 1,227 & 0,0406 & 1,1743 \\
\hline Açude Flexas & 0,2725 & 0,367 & 4,4909 & 3,4886 & 0,0262 & 1,2559 \\
\hline Açude M. Vieira & 0,4886 & 0,2806 & 5,1677 & 5,0581 & 0,0753 & 1,3922 \\
\hline B. Pau dos ferros & 0,3898 & 0,4683 & 6,8175 & 5,0997 & 0,214 & 4,7031 \\
\hline
\end{tabular}

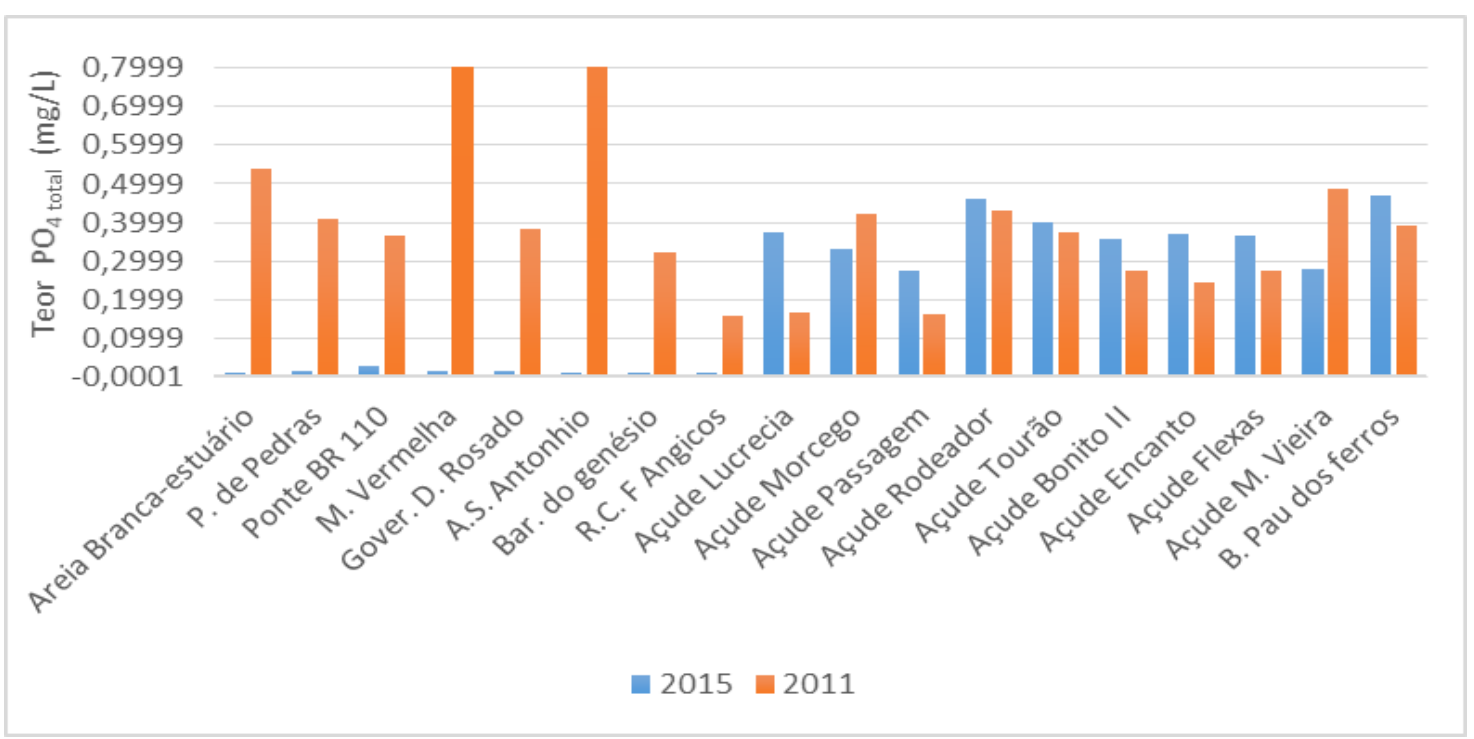

Gráfico 2: Teores de $\mathrm{PO}_{4}$ total nos 18 pontos analisados.

Como pode ser visto no Gráfico 2 o teor de $\mathrm{PO}_{4}$ total na maioria dos pontos diminuiu, consideravelmente, nos últimos cinco anos. Dentre os pontos destacam-se M. Vermelha e A.S. Antonhio, onde se observou os valores mais desproporcionais. Os teores de $\mathrm{PO}_{4}$ total tem duas grandes fontes para os recursos hídricos superficiais, as quais se diferenciam de acordo com a área destes estar na zona urbana ou na zona rural. Segundo a resolução CONAMA n 357/2005, 
o valor máximo para fósforo total em ambiente lêntico é $0,020 \mathrm{mg} / \mathrm{L}$ e 0,025 mg/L em ambiente intermediário para águas doces de classe I, em águas de classe III para ambiente lêntico é 0,05 $\mathrm{mg} / \mathrm{L}$ e $0,075 \mathrm{mg} / \mathrm{L}$ em ambiente intermediário. De acordo com estes limites os resultados mostram que todos os pontos em 2011 e 60 \% dos pontos em 2015 estão acima dos limites permitidos.

Nas zonas urbanas a principal fonte são os esgotos domésticos e na zona rural a principal fonte é o carreamento de resíduos da agricultura (fertilizantes). Assim a ausência de precipitação pluviométrica impediu o carreamento deste elemento e provocou o abaixamento na maioria dos locais examinados mais próximo da zona urbana (metade a esquerda no gráfico). Nos outros locais os resultados são muito maiores e mais próximos devido a presença de esgotos domésticos serem o efeito predominante na ausência de precipitações pluviométricas e este variar de acordo com a densidade populacional, o local do recurso hídrico e com o tipo de esgoto. Outra possível explicação é a ocorrência das primeiras precipitações pluviométricas de 2015 nos locais onde o nível aumentou. Neste sentido é interessante observar que em todos os pontos onde ocorreram valores de fósforo maior em 2015 se encontram próximo a região serrana, onde a ocorrência de precipitações pluviométricas esparsas é mais comum.

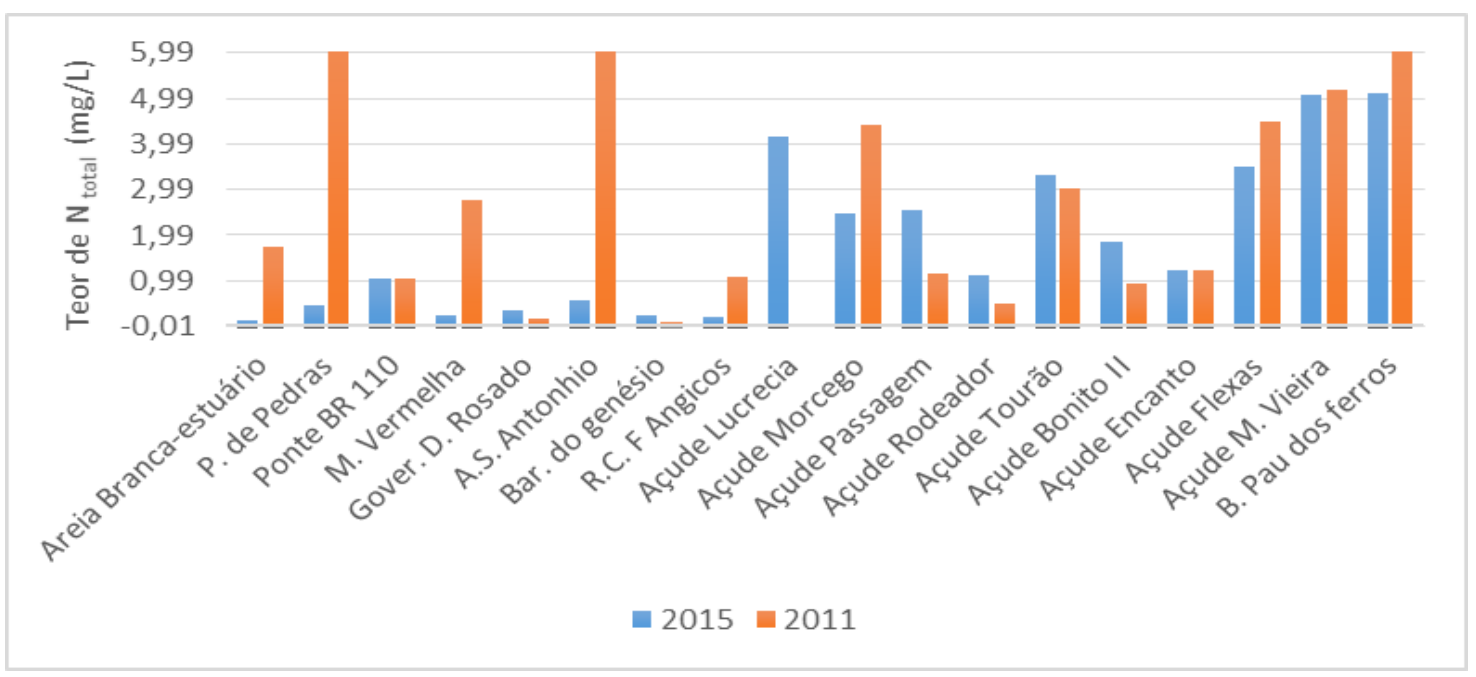

Gráfico 3: Teores de $\mathrm{N}$ total nos dezoito pontos analisados.

Segundo Oyama e Nobre (2003), as bacias hidrográficas da região semiárida do Brasil apresentam algumas características que potencializam o aporte de nutrientes aos reservatórios da região. A presença de solos rasos com pouca cobertura vegetal, devido à vegetação esparsa e de pequeno porte do bioma caatinga, associados a eventos chuvosos concentrados em poucos dias do ano, fazem com que os solos da região se tornem bem lixiviados e os nutrientes sejam carreados em grande escala para os corpos d'água superficiais, durante o período chuvoso.

Em seu estudo sobre a influência da poluição difusa e do regime hidrológico peculiar do semiárido na qualidade da água de um reservatório tropical, OLIVEIRA (2012) diz que no período chuvoso as concentrações de fósforo total e fósforo solúvel reativo registradas no reservatório Dourado foram elevadas, reflexo da capacidade do reservatório, em reter parte da carga de nutrientes exportada a partir da bacia de drenagem.

De acordo com Reynolds (2006), a diminuição das concentrações de fósforo total e fósforo solúvel reativo, durante o período de seca pode ser atribuída ao consumo desses nutrientes pela biomassa algal, a qual apresentou um crescimento progressivo durante a seca, semelhante ao observado no reservatório Tapacurá, com períodos de baixas concentrações de fósforo solúvel reativo coincidindo com florações da biomassa algal (Bouvy et al., 2003).

Como pode ser observado no Gráfico 3 o teor de $\mathrm{N}_{\text {total }}$ no ano de 2015 é bastante inferior ao teor do ano de 2011, onde destacam-se pela desproporcionalidade dos valores os pontos de P. de Pedra, M. Vermelha, A. S Antonhio e o açude Lucrécia no decorrer de julho de 2011 à julho de 2015. O nitrogênio total não é padrão de referência na resolução CONAMA nº 357/2005, mas valores altos podem levar os recursos hídricos a eutrofização. 


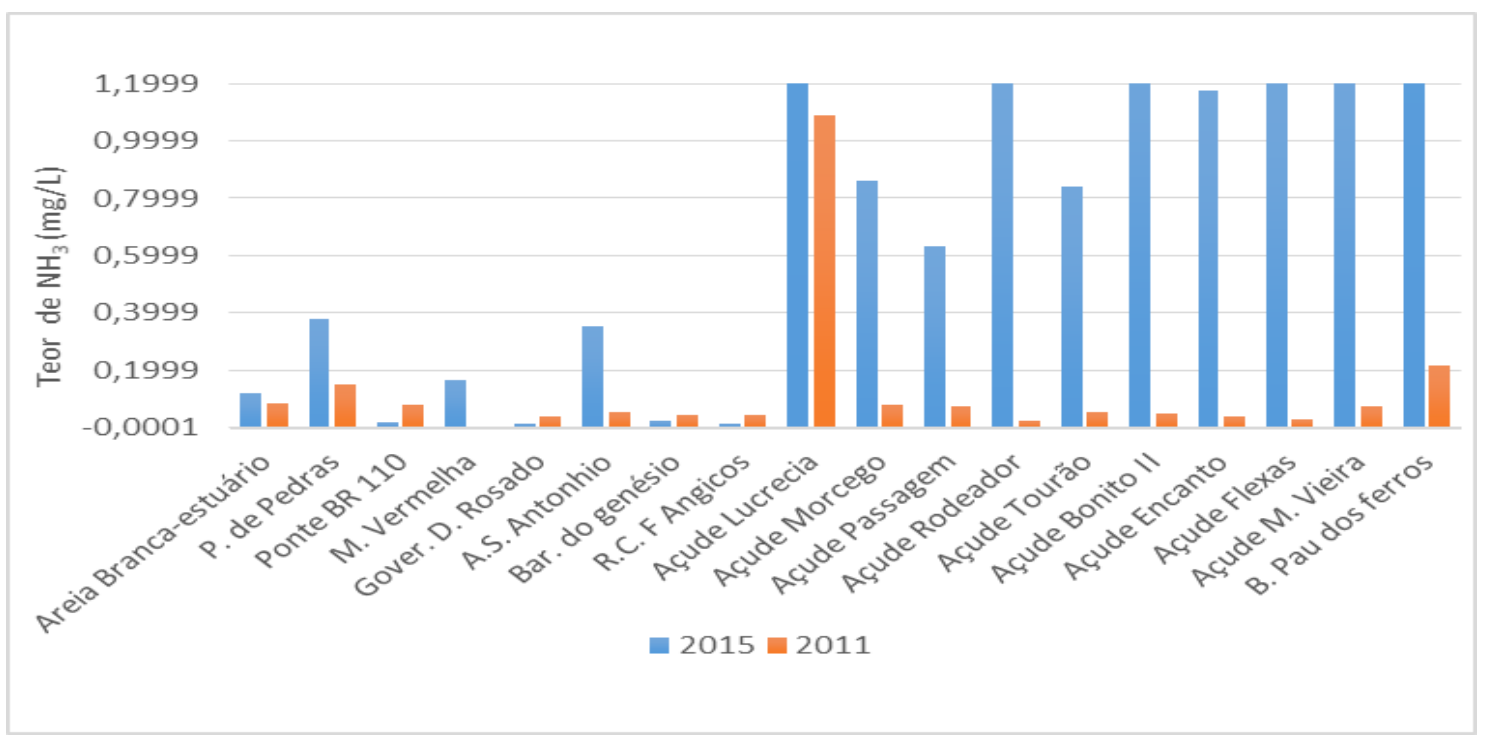

Gráfico 4: Teores de $\mathrm{NH}_{3}$ nos 18 pontos analisados.

No Gráfico 4 observa-se que o teor de $\mathrm{NH}_{3}$ tem aumentado no decorrer de 2011 à 2015 em um nível preocupante, onde apesar de todos os valores serem bastante desproporcionais, destaca-se o açude Lucrécia e B. Pau dos ferros (Tabela 1) com valores muito mais elevados em 2015 quando comparado a julho de 2011. De acordo com a resolução CONAMA n ${ }^{\circ}$ 357/2005, os valores máximos de nitrogênio amoniacal para as águas de classe II são 0,70 mg/L. Como o $\mathrm{pH}$ da maioria dos pontos estudados é superior a 8 (ÁGUA AZUL, 2012) pode-se concluir que a maioria dos pontos estão com os níveis de amônia acima do s limites estabelecidos na legislação.

Segundo SOUZA (2008), na natureza são poucas as formas vivas capazes de promover a fixação biológica do $\mathrm{N}_{2}$. Alguns desses organismos têm vida livre e entre eles podem se citar certas algas azuis, como o Nostoc, e bactérias do gênero Azotobacter e Clostridium.

Alguns estudiosos relacionam a presença de cianobactérias com a vazão dos reservatórios no semiárido, os resultados obtidos indicam que a dominância de cianobactérias nestes reservatórios do semiárido Potiguar, durante o período de estiagem atípica, parece ter sofrido grande influência de outros fatores hidrológicos, tais como, a relação volume/área além da disponibilidade de luz e nutrientes. Nos reservatórios estudados, existem regiões dominadas por cianobactérias filamentosas heterocitadas e não-heterocitadas e Microcystis spp. A redução do volume e escassa profundidade dos reservatórios na estiagem parecem promover a alta turbidez diminuindo a disponibilidade de luz e favorecendo a prevalência e aumento da biomassa de espécies de cianobactérias selecionadas para estas condições ambientais. Nos reservatórios do semiárido potiguar investigados, a estiagem prolongada, alta evaporação, longo tempo de residência e altos níveis de nutrientes, favorece a condição eutrófica e reduzida transparência. (COSTA et al., 2009,).

Naselli-Flores (2003) relatou que a redução do volume (90\%) dos reservatórios da Sicília durante o período de primavera, interferiu fortemente na dinâmica do fitoplâncton e nutrientes dos reservatórios, isto devido a alta demanda de usos no verão, o que levou ao estabelecimento do fenômeno da eutrofização e seleção de espécies de cianobactérias que causam danos à saúde humana. E, ainda, segundo Smith (1996), a baixa disponibilidade de luz é um importante fator para promover a dominância de cianobactérias.

Os volumes encontrados nos reservatórios estudados concordam com estes resultados e com os determinados neste artigo conforme ilustra a Tabela 2 com os dados de reservatórios estudados e a Figura 1 com dados gerais do estoque d'água no Estado do Rio Grande do Norte e no nordeste. 
Tabela 2. Comparação entre volume e porcentagem dos reservatórios de água em um dos pontos analisados no período de 2011 a 2015.

\begin{tabular}{cccccccc}
\hline Projeto & $\begin{array}{c}\text { Capacidade } \\
\left(\mathrm{m}^{3}\right)\end{array}$ & Vol. $\left(\mathrm{m}^{3}\right)$ & $\mathbf{( \% )}$ & Data & $\begin{array}{c}\text { Vol. } \\
\text { atual } \\
\left(\mathrm{m}^{3}\right)\end{array}$ & $\mathbf{( \% )}$ & Data \\
\hline $\begin{array}{c}\text { Açude } \\
\text { Lucrécia }\end{array}$ & 24.754 .574 & 16.639 .580 & 67,22 & $03 / 05 / 11$ & 635.789 & 2,57 & $03 / 06 / 15$ \\
\hline $\begin{array}{c}\text { Açude } \\
\text { Marcelin } \\
\text { o Vieira }\end{array}$ & 11.200 .125 & 11.200 .125 & 100,00 & $31 / 05 / 11$ & 1.800 .009 & 16,07 & $03 / 06 / 15$ \\
\hline $\begin{array}{c}\text { Barragem } \\
\text { Armando } \\
\text { R. G. }\end{array}$ & $2.4 \times 10^{8}$ & $2.4 \times 10^{8}$ & & & & & \\
\hline $\begin{array}{c}\text { Açude } \\
\text { Arapuã }\end{array}$ & 4.295 .000 & 4.295 .000 & 100,00 & $31 / 05 / 11$ & 260.100 & 6,06 & $03 / 06 / 15$ \\
\hline
\end{tabular}

Fonte: Site DNOCS

http://www.dnocs.gov.br/ dnocs/php/comunicacao/monitoramento_de_reservatorios.php

Em concordância com o Gráfico 2, a Tabela 2 mostra a correlação entre o nível da água nos reservatórios nos açudes de Lucrécia e Marcelino Vieira e os teores de fósforo obtidos por meio de análise adequada nos mesmos. Assim como o abaixamento do nível de água em diversos reservatórios do semiárido contribui para a diminuição dos níveis de fósforo e aumento da $\mathrm{NH}_{3}$, sendo a barragem Armando Ribeiro Gonçalves a maior da região potiguar e que se encontra com $1 / 4$ da capacidade um bom exemplo do problema por que passa a região estudada.

\section{CONCLUSÕES}

A correlação entre os resultados de $\mathrm{PO}_{4 \text { total, }} \mathrm{N}$ total e nitrogênio amoniacal e o volume $\left(\mathrm{m}^{3}\right)$ de alguns dos açudes da região mostra que o período de estiagem aumentou o nível destes poluentes nos corpos d'água. Este aumento de poluição é fortemente influenciado pela espacialidade (local dos pontos) e suas respectivas densidades populacionais e atividades econômicas, ás quais determinam a qualidade e a quantidade de poluentes que são carreados pela chuva ou descarregados nos recursos hídricos pelos esgotos domésticos. Isso fez com que o teor de amônia, que é um indicador de fonte de poluição recente, apresente-se alto na maioria dos pontos. Por outro lado, o teor e $\mathrm{PO}_{4}$ total e $\mathrm{N}_{\text {total }}$ diminuiu em muitos pontos, sendo que essa diminuição durante o período de seca pode ser atribuída ao consumo desses nutrientes pela biomassa algal e a falta de carreamento de resíduos de pesticidas e também de matéria orgânica (solo) para os recursos hídricos.

\section{CHANGE OF CONCENTRATIONS OF NITROGEN AND PHOSPHORUS I N RI VER BASI N APODI-MOSSORÓ IN THE LIGHT OF THE EFFECTS OF DROUGHT AND SPATI ALITY.}

\section{ABSTRACT}

The river Apodi-Mossoró, Brazil's second largest river, has suffered great losses because of its high pollution, as a result of the anthropic action around it and conditions that involves. Among the various pollutants, which affect the River, the present work proposes to relate the content of 
nitrogen and phosphorus compounds with the flow the water catchment area of the river ApodiMossoró has suffered in the last five years. For the same colorimetric analyses were made of total, total $\mathrm{N}$ and PO4 ammoniacal nitrogen in eighteen points of collection at dams, dams and bathed by the river properties, the results were correlated to the climate factor of semi-arid region. The results showed that the temperature of the semi-arid promotes evaporation of their reservoirs and the long period of drought causes shells exhibit low water volume, because of these factors the phosphorus content has decreased in rural areas, because there was no agricultural waste being washed (fertilizer) which is the main source of this nutrient in the area, in the urban area where the main source are the domestic sewage, There was minimal change or increase. The same can be said with respect to nitrogen content in the water of the areas examined, because the nitrogen and phosphorus exhibit similar contamination sources. On the other hand, ammonia for being an indicator of pollution source next, features high on their levels in analyzed points, as there is accumulation of the same due to water shortages.

Keywords: surface water; quality indicators; water body

\section{AGRADECI MENTOS}

A Universidade do Estado do Rio Grande do Norte (UERN) e aos laboratórios de Biologia I, de Eletroquímica e Química Analítica (LEQA) e do Laboratório de Catálise, Ambiente e Materiais (LACAM).

\section{REFERENCI AS BI BLI OGRÁFI CAS}

ALABURDA, J.; NISHIHARA, L. Presença de composto de nitrogênio em águas de poços. Rev. Saúde Pública, 32, n. 2, p. 160-165, Abr., 1998.

APHA - American Public Health Association. Standart methods for the examination of water and wastewater. Washington; 2005.

BOUVY, M. et al. Limnological features in Tapacurá reservoir (northeast Brazil) during a severe drought. Hydrobiologia, p. 115-130. 2003.

BRASIL.Ministério do Meio Ambiente. Conselho Nacional do Meio Ambiente. Resolução nº. 357, de 2005. CONAMA: resoluções e outros atos. Brasília, DF, 17 mar. 2005. Disponível em: < http://www.mma.gov.br/port/conama/legiabre.cfm?codlegi=459 > Acesso em: 27 Ago. 2015.

CASTRO, S. S. L. ; OLIVEIRA, T. M. B. F. ; MORAIS, P. R. F. ; SOUZA, L.D.. Impact study of untreated domestic effluents discharge in the rivers through WQI: a real case in the Apodi/Mossoró basin. Química no Brasil. v. 5, p. 23-31, 2011.

CASTRO, S. S. L., SOUZA, L.D.; MARTINS, D. F. F.; OLIVEIRA, T. M. B. F.; BATISTA, R.S. Qualidade físico-química das águas da bacia do Rio Apodi/Mossoró. Química no Brasil, v.2, p.61 - 74, 2007.

CASTRO, S.S.L. ; SOUZA, L.D. ou SOUZA, L. ; DANTAS, I. M. ; SILVA, G.H.G. ; CASTRO, R. S.. Sustainable Use of Water in Tropics and Subtropics: The Case of Apodi/Mossoró River Basin in the Brazilian Semi-Arid. Em: Carolina Bilibio; Oliver Hensel; Jeferson Francisco Selbach. (Org.). Sustainable Water Management in the Tropics and 
Subtropics - and Case studies in Brasil. 1ed.jaguarão. : Fundação Universidade Federal do Pampa, Unikassel, PGCult-UFMA. 2012 B.v. 3, p. 537-561.

CASTRO, SSL ; SOUZA, L.D. ; SILVA, L. M.. Monitoramento espaço temporal da qualidade das águas da bacia hidrográfica do rio Apodi/Mossoró - RN. Química no Brasil. 2012 A.

COSTA, I. A. S. et al. Dinâmica de cianobactérias em reservatórios eutróficos do semi-árido do Rio Grande do Norte. Oecologia Brasiliensis (Impresso), p. 382-401, 25 de set. de 2009.

ECO4U. Uma das mais extensas redes fluviais do mundo: conheca as 12 regioes hidrograficas brasileiras. Disponível em: https://eco4u.wordpress.com/tag/bacia-atlanticonordeste-oriental/. Acesso em: 24 de set. de 2015.

MORAIS, L. A. ; CASTRO,S. S. L ; SOUZA, L. . Impactos dos efluentes urbanos e industriais na qualidade da água da bacia do rio apodi/mossoró no seu baixo curso. In: 15 ENCONTRO NACIONAL DE QUÍMICA ANALÍTICA E 3 CONGRESSO IBEROAMERICANO DE QUÍMICA ANALÍTICA, 2009, Salvador.

NASELLI-FLORES, L. \& BARONE, R. Steady stade assemblages in a Mediterranean hypertrophic reservoir. The role of Microcystis ecomorphological variability in maintaining an apparent equibrium. Hydrobiologia 502: 133-143, 2003.

OLIVEIRA, E. T. Bacia hidrográfica do rio apodi-mossoró: macroinvertebrados como bioindicadores e a percepção ambiental dos pescadores e marisqueiras do seu entorno. 2009, p. 115. Dissertação (Mestrado em desenvolvimento e meio ambiente) - Programa Regional de Pós-Graduação Em Desenvolvimento e Meio Ambiente, Universidade Federal da Paraíba, Paraíba, 2001.

OLIVEIRA, N. P. A influência da poluição difusa e do regime hidrológico peculiar do semiárido na qualidade da água de um reservatório tropical. 2012, 100 f. Dissertação (Mestrado em engenharia sanitária) - Universidade Federal do Rio Grande do Norte, Natal. 2012.

OLIVEIRA, T. M. B. F.; SOUZA, L. S.; CASTRO, S. S. L.; Dinâmica da série nitrogenada nas águas da bacia hidrográfica Apodi/Mossoró - RN - Brasil. Revista Eclética Química. v. 34, n. 3, 2009. Disponível em: <http://www.scielo.br/pdf/eq/v34n3/02.pdf>. Acesso em: 15 set. 2011.

OYAMA, M. D. ; NOBRE, C. A. Climatic consequences of a largue-scale desertification in Northeastern Brazil: a GCM Simulation study. Journal of Climate, p. 1718-1730, 13 Feb. 2004

PADISÁK, J.; REYNOLDS C.S. Shallow lakes: the absolute, the functional and the pragmatic. Hydrobiologia, P. 506-509. 2003.

PIVELI, R. P. ; KATO, M. T. . Qualidade das Águas e Poluição: Aspectos Físico-Químicos. 01. ed. São Paulo/SP: ABES - Associação Brasileira de Engenharia Sanitária e Ambiental, 2005. v. 01. 285 p.

PROGRAMA ÁGUA AZUL. Disponível em http://programaaguaazul.rn.gov.br/. Acessado em 29 de set. de 2015.

RESENDE, A. V. Agricultura e qualidade da água: Contaminação da água por nitrato. 2002. 29 p. Ministério da agricultura, pecuária e abastecimento, Distrito Federal. 
REYNOLDS C. Ecology of Phytoplankton, Cambridge University Press, Cambridge. 2006.

SILVA A. G.; SOUZA L. D. Efeitos Antropicos e Sazonais na qualidade da água do rio do Carmo. Revista HOLOS, v. 5, p. 131. 2013.

SMITH, P.T. Light and nutrients effects on the relative biomass of blue-green algae in lake phytoplankton. Canadian Journal Fish and Aquatic sciences, p. 148-153, 10 abr. 1996.

SOUZA, F. A. Agricultura natural/orgânica como instrumento de fixação biológica e manutenção do nitrogênio no solo. Um modelo sustentável de MDL. In: Anais do CONGRESSO BRASILEIRO DE DIREITO AMBIENTAL, 13. 2008, São Paulo,. São Paulo: Instituto O Direito por um Planeta Verde, 2008, p. 139-156. 